\title{
Effect of soil salinity on growth, metal distribution and photosynthetic performance of two Lycium species
}

\author{
V.L. DIMITROVA*, M.M. PAUNOV**, V. GOLTSEV ${ }^{* *}$, M.P. GENEVA**,+, and Y.K. MARKOVSKA** \\ Biotree, 1331 Sofia, Bulgaria* \\ Faculty of Biology, University of Sofia, 1164 Sofia, Bulgaria** \\ Department of Plant Soil Interactions, Institute of Plant Physiology and Genetics, Bulgarian Academy of Sciences, \\ 1113 Sofia, Bulgaria ${ }^{* * *}$
}

\begin{abstract}
The effect of salinity on gas exchange and fluorescence characteristics in Lycium barbarum and Lycium chinense grown on nonsaline and saline soils was investigated. The distribution of $\mathrm{Na}^{+}$between three types of substrates and different organs showed acropetal concentration gradient for $\mathrm{Na}^{+}$accumulation only in L. barbarum grown on peat-moss-perlite and saline soil. Selective uptake of $\mathrm{K}^{+}$over $\mathrm{Na}^{+}$in the L. barbarum leaves was established. All plants grown on saline soil showed a slight inhibition of PSII activity as revealed by the quantum yield of the primary photochemical reaction. Intersystem electron transport, reduction of the end electron acceptors, and the performance index of photosynthesis declined to a greater extent in $L$. barbarum than that in $L$. chinense. The higher tolerance of $L$. chinense to salt stress was accompanied with the higher overall photosynthetic performance.
\end{abstract}

Additional key words: chlorophyll fluorescence; metal contents; net photosynthesis; salinity.

\section{Introduction}

Salinity in soil or water is one of the major negative factors of the environment, especially in arid and semiarid regions, and can severely limit crop production. In recent decades, the investigations are focused on studying biochemical and physiological traits (Munns and Richards 2007, Koyro et al. 2014), identification of key genes and/or discovery of distinctive molecular markers in a great number of agricultural crops for improving their salt tolerance (Kosová et al. 2011). Besides the naturally formed saline and sodic soils, so-called secondary salt-affected soils occur due to the application of different agricultural practices and continue to grow (Munns 2011). According to FAO Land and Plant Nutrition Management Service, the total surface of the saline regions of the world is the almost $397 \times 10^{6}$ ha and $2 \%$ of them are salt-affected (Dajič 2006). Deeper soil pollution and salinization require utilization of alternative fast-growing woody species with deep root systems and the ability to grow in nutrient-poor soil. Munns (2011) proposed that increased salt tolerance of perennial species (such as woody species or shrubs) used for fodder, biofuel or economic important bioactive products is a key component in reducing the spread of secondary salinity, while increased salt tolerance of crops directly improves production in soils with primary salinity.

Lycium L. (Solanaceae) is a genus of approximately 80 species distributed mainly in Asia, America, and Africa (Bernardello 1986, Miller 2002, Levin and Miller 2005). Lycium species are long-lived perennial shrubs which produce red or purple, fleshy berries. L. barbarum and $L$. chinense are a unique nutritional and medicinal food. The plants are used in traditional Chinese medicine for the treatment of pneumonia, cough, inflammation, and diabetes mellitus. In some Asian countries, the fruits are used as a tonic and invigorating agent, stimulating the immune system. In Bulgaria, L. barbarum L. is cultivated as an ornamental shrub, for forming hedges, and also for stabilisation of the soil and landslides. The effects of the fruits are widely popularised in Bulgaria during the past few years and the species is strongly recommended by some private companies for a cultivation (under the name “Goji Berry") (Petrova et al. 2013). As Zheng et al (2010) confirmed, L. barbarum L. is the only halophytic species in the genus Lycium and its physiological characteristics of drought and salt tolerance make it an ideal plant for preventing soil desertification and alleviating the soil salinity. Overexploitation of Lycium natural habitats

\footnotetext{
Received 12 July 2017; accepted 18 May 2018

${ }^{+}$Corresponding author; e-mail: boykova2@yahoo.com

Abbreviations: $\mathrm{Chl}$ - chlorophyll; $\mathrm{DI}_{\mathrm{o}} / \mathrm{RC}$ - energy flux dissipation per reaction center; $E$ - transpiration rate; $\mathrm{F}_{\mathrm{m}}-\mathrm{maximal}$ fluorescence yield of the dark-adapted state; $\mathrm{F}_{0}$ - minimal fluorescence yield of the dark-adapted state; M-PEA - multifunctional plant efficiency analyzer; OEC - oxygen-evolving complex; PF - fast chlorophyll $a$ fluorescence; $\mathrm{PI}_{\mathrm{ABS}}-$ performance index; $\mathrm{PI}_{\text {total }}-$ total performance index; PMP - peat-moss-perlite; $P_{\mathrm{N}}$ - net photosynthetic rate; $\mathrm{PQH}_{2}$ - reduced plastoquinone; $\mathrm{Q}_{\mathrm{A}}-$ primary quinone acceptor of PSII; ROS - reactive oxygen species; WUE - water-use efficiency; $\Phi_{\mathrm{P}_{\mathrm{o}}}$ - quantum yield of the primary photochemistry reaction; $\Phi_{\mathrm{Eo}}-$ quantum yield of the electron transport between PSII and PSI; $\Phi_{\text {Ro }}$ - quantum yield for reduction of the end electron acceptors of PSI.
} 
caused its deterioration and decreased existing populations (Liu et al. 2012). That is why the development of micropropagation technologies is necessary in future.

In the present study, pot experiments were carried out to investigate differences in the growth between L. barbarum and L. chinense Mill. plants cultivated ex vitro on peat-moss-perlite (PMP) and two types of saline soils for a period of two vegetative seasons. PMP is preferred as a substrate for long-term cultivation of Lycium plants in the private companies. For this reason, differences in the distribution of $\mathrm{Mg}^{2+}, \mathrm{Ca}^{2+}, \mathrm{Na}^{+}$, and $\mathrm{K}^{+}$between available fractions from three substrates and different organs, as well as photosynthetic performance of both species were investigated in order to understand the salt resistance mechanisms of Lycium species. The hypothesis that both species adapted any sort of avoidance mechanisms towards increasing substrate salinity was tested.

\section{Materials and methods}

Plant material: Seeds and in vivo explants from the species of $L$. barbarum L. and L. chinense Mill. were used for developing of in vitro multiplication protocol (Dimitrova et al. 2016). Seedlings derived from in vitro micropropagation were cultivated in plastic pots filled with $1.5 \mathrm{~kg}$ of PMP substrate (type 0 ) and two soils (type 1 and 2 ). The experiment was set as three treatments, with seven replications and was conducted in a glasshouse (natural sunlight, temperatures of $15-35^{\circ} \mathrm{C}$, relative humidity of 40 $65 \%$ ) for two vegetative seasons (from 1 April 2015 to 30 July 2016). The soils used in this study were taken from an area located in the vicinity of the village Belozem, Bulgaria $\left(42^{\circ} 20^{\prime} \mathrm{N}, 25^{\circ} 3^{\prime} \mathrm{E}\right)$. A sampling strategy was carried out from the surface and at depths of 30-60 cm in different locations of the areas. As a control soil (type 0) PMP (2:1, $\mathrm{v} / \mathrm{v})$ was used. The basic component of peat moss was Sphagnum, supplemented with shavings, ground limestone, sand and moisture holding agent. The soil type 2 possessed exchangeable $\mathrm{Na}^{+}$content about 5 times higher, the sodium adsorption ratio (SAR) was about 4.5 times higher, and electrical conductivity of $14.0 \mathrm{mS} \mathrm{cm} \mathrm{cm}^{-1}$ was about 2 times higher in comparison with the soil type 1 (Ivanova et al. 2014). On the basis of agrochemical characteristics, the soil type 1 was characterized as nonsaline, while the soil type 2 might be determined as middle alkaline (Referative basic data 2009). The pots were irrigated daily with tap water to exceeding field capacity of the soils.

Growth parameters: At the end of the experiment, the plant samples were collected, washed with tap water, and rinsed with distilled water before being separated into shoots and roots. Dry mass (DM) of shoots and roots were determined after oven drying $\left(60^{\circ} \mathrm{C}\right)$ for $2 \mathrm{~d}$ until constant mass was obtained.

Plant and soil metal analysis: Total $\mathrm{Mg}^{2+}, \mathrm{Ca}^{2+}, \mathrm{Na}^{+}$, and $\mathrm{K}^{+}$contents in the soil samples were measured. The soil bioavailable metal fraction (free metal ions, soluble metal complexes, and metals adsorbed to inorganic soil constituents at ion-exchange sites) was determined by extraction tests (Doumett et al. 2008). Total metal content in available fractions and plant organ samples was determined by atomic absorption spectrophotometric analysis (PerkinElmer 5000, UK), after acidic digestion with suprapur grade Fluka reagents (Doumett et al. 2008).

Gas-exchange measurements: $\operatorname{Netphotosyntheticrate}\left(P_{\mathrm{N}}\right)$ and transpiration rate $(E)$ were measured simultaneously on 30 July 2016 using a portable gas analyser $L i-6400$ (Li-Cor Inc., Lincoln, NE, USA), with a red-blue LED light source. Measurements were made in the late morning hours between 10:00 and 12:00 under standard conditions [air temperature of $25^{\circ} \mathrm{C}$, air humidity of $50 \%$ inside the gasexchange cuvette, PAR of $1,000 \mu \mathrm{mol}$ (photon) $\mathrm{m}^{-2} \mathrm{~s}^{-1}$, and ambient concentration of $\left.350 \mu \mathrm{mol}\left(\mathrm{CO}_{2}\right)\right]$. Five to seven middle-aged, attached leaves of plants at each treatment were measured and averaged. The following index was calculated: water-use efficiency $\left(\mathrm{WUE}=P_{\mathrm{N}} / E\right)$.

Chlorophyll (Chl) fluorescence measurements: The physiological state of plants at each treatment was monitored by fast Chl $a$ fluorescence (PF) induction transients recorded by fluorometer M-PEA (Hansatech Instruments Ltd., King`s Lynn, Norfolk, UK) after 30-min dark adaptation of seven different plants and three middleaged leaf replicates. For the measurements, a red light beam $(625 \mathrm{~nm})$ was applied for $10 \mathrm{~s}$ at a light intensity of 4,000 $\mu \mathrm{mol}$ (photon) $\mathrm{m}^{-2} \mathrm{~s}^{-1}$ (Strasser etal.2004, Stirbet et al.2014). The rising in PF during an illumination period of about $1 \mathrm{~s}$ is described by the so-called transient "JIP" curve comprised of several characteristic points $(\mathrm{O}, \mathrm{J}, \mathrm{I}$, and $\mathrm{P})$ (Strasser et al. 1995, 2004). Each point represented a quasi-stationary state in the fluorescence emission. At the beginning of the fluorescence measurement (point $\mathrm{O}$ ), most of the $\mathrm{P}_{680}$ are opened and the fluorescence is minimal $\left(\mathrm{F}_{0}\right)$, whereas at point $\mathrm{P}$ the fluorescence is maximal $\left(\mathrm{F}_{\mathrm{p}}\right)$ as most of the $\mathrm{P}_{680}$ are closed. Points J and I reflected the accumulation of reduced forms of $\mathrm{Q}_{\mathrm{A}}$ and $\mathrm{PQH}_{2}$, respectively. PSII activity is further investigated by calculating the parameters of $\mathrm{PF}$ - the quantum yield of the primary photochemistry reaction $\left(\Phi_{\mathrm{Po}}\right)$, the quantum yield of the electron transport between PSII and PSI $\left(\Phi_{\mathrm{Eo}}\right)$, and the quantum yield for reduction of the end electron acceptors of PSI $\left(\Phi_{\mathrm{Ro}}\right)$. These parameters represent the ratio between the energy of absorbed photons by PSII and the energy used in photochemical reactions (Strasser et al. 2004, Goltsev et al. 2014). In addition, energy flux dissipation per reaction center $\mathrm{DI}_{\mathrm{o}} / \mathrm{RC}$ and the photosynthetic performance indexes, $\mathrm{PI}_{\mathrm{ABS}}$ and $\mathrm{PI}_{\text {total }}$, were also investigated.

Statistical analysis: All data reported in this work were a mean value of at least five to seven independent experiments. The mean values $\pm \mathrm{SD}$ and an exact number of experiments are given in the legends of the figures. The significance of differences between control and each treatment was analyzed by Fisher's LSD test $(p \leq 0.05)$ after performing analysis of variance (ANOVA) multifactor analysis (Statgraphics Plus, version 5.1 for Windows). 


\section{Results}

Effect of soil salinity on seedling growth: Our results showed that with increasing salinity, root and shoot DM of $L$. chinense increased, while root and shoot DM of $L$. barbarum decreased. The shoot DM of $L$. barbarum was 2.6 times higher than that of $L$. chinense after cultivation of both type of plants on PMP (Table 1).

Table 1. Changes in total dry mass (DM) of shoots and roots of Lycium barbarum and Lycium chinense, cultivated for two vegetation seasons on peat-moss-perlite (type 0), nonsaline (type 1), and saline (type 2) soils in a glasshouse. Values are means $\pm \mathrm{SD}, n=5-7$; different letters indicate significant differences assessed by Fisher LSD test $(p \leq 0.05)$ after performing one-way ANOVA analysis.

\begin{tabular}{lll}
\hline Treatment & $\begin{array}{l}\text { Total shoot dry mass } \\
\text { [g plant }^{-1} \text { ] }\end{array}$ & $\begin{array}{l}\text { Total root dry mass } \\
\text { [g plant }^{-1} \text { ] }\end{array}$ \\
\hline $\begin{array}{l}\text { Lycium barbarum } \\
\text { Type (0) }\end{array}$ & $0.808 \pm 0.079^{\mathrm{a}}$ & $0.276 \pm 0.027^{\mathrm{a}}$ \\
Type (1) & $2.728 \pm 1.069^{\mathrm{b}}$ & $4.148 \pm 0.512^{\mathrm{b}}$ \\
Type (2) & $0.588 \pm 0.280^{\mathrm{c}}$ & $0.900 \pm 0.079^{\mathrm{c}}$ \\
Lycium chinense & & \\
Type (0) & $0.305 \pm 0.022^{\mathrm{a}}$ & $0.291 \pm 0.022^{\mathrm{a}}$ \\
Type (1) & $0.204 \pm 0.131^{\mathrm{a}}$ & $0.288 \pm 0.044^{\mathrm{a}}$ \\
Type (2) & $0.288 \pm 0.169^{\mathrm{b}}$ & $0.358 \pm 0.039^{\mathrm{b}}$ \\
\hline
\end{tabular}

Effect of soil salinity on the distribution of metals: The bioavailable amount of target alkaline and alkaline metals present in the fractions of the soils before planting showed that $\mathrm{Mg}^{2+}, \mathrm{Ca}^{2+}, \mathrm{Na}^{+}$, and $\mathrm{K}^{+}$prevailed in control and saline soil (Table 2). The ratio $\mathrm{K}^{+} / \mathrm{Na}^{+}$was the highest and $\mathrm{pH}$ was acidic in control, while $\mathrm{pH}$ was alkaline in nonsaline and saline soils. Higher $\mathrm{Ca}^{2+}$ and especially $\mathrm{Na}^{+}$contents were found in the fractions of control and nonsaline and saline soils after harvesting of both type of plants. The obtained ratio of $\mathrm{K}^{+} / \mathrm{Na}^{+}$in the bioavailable fractions from control and nonsaline soil was reduced about 7 times and 2-3.5 times after harvesting of L. barbarum and $L$. chinense, while in the fraction from saline soil was enhanced about 5-3 times, respectively. The $\mathrm{pH}$ values of the bioavailable fractions of nonsaline and saline soils decreased from alkaline to middle acidic, while $\mathrm{pH}$ of the bioavailable fraction of control increased slightly (Table 2). The accumulation of $\mathrm{Na}^{+}$prevailed in the roots of both species grown on control and saline soil. The content of $\mathrm{K}^{+}$in the roots of $L$. chinense grown on nonsaline soil was two times higher than that in the roots of L. barbarum. Nevertheless, the obtained ratio of $\mathrm{K}^{+} / \mathrm{Na}^{+}$in the roots of L. chinense was 1.9 time higher (8.89) than that in L. barbarum (4.67) (Table 3). The results showed that both plant species grown on nonsaline soil avoided stress by excreting excess contents of alkaline metals in the rhizosphere zone (Table 2). The accumulation of $\mathrm{Na}^{+}$in the leaves of L. chinense was higher than that of L. barbarum grown on control, nonsaline, and saline soils at the end of the second vegetative season. $\mathrm{K}^{+}$prevailed in the leaves of $L$. barbarum grown on three types of substrates in comparison to $L$. chinense. That is why the ratio $\mathrm{K}^{+} / \mathrm{Na}^{+}$ was higher in the leaves of the former species than that of the latter one (Table 4). Our results showed acropetal concentration gradient of $\mathrm{Na}^{+}$distribution between soil pore water and plant tissues only for $L$. barbarum grown on control and saline soil (Tables 2, 3, 4). Irrespective of salt exclusion by root membranes, leaf content of $\mathrm{K}^{+}$and $\mathrm{Na}^{+}$ in both species grown on nonsaline soil remained similar as compared to these grown on saline soil (Table 4).

Effect of soil salinity on photosynthetic gas exchange: The results showed gradually enhancing of $P_{\mathrm{N}}$ in the leaves of $L$. barbarum grown on different soil substrates, while in L. chinense the values declined (Fig. 1A). The same tendency was found for $E$ in $L$. barbarum. This parameter was reduced in the leaves of $L$. chinense grown on saline soil in comparison to nonsaline soil (Fig. 1B). The values of WUE decreased approximately twice in L. barbarum grown on saline soil than that of nonsaline soil, while in $L$. chinense these differences were insignificant (Fig. 1C).

Table 2. Bioavailable alkaline and alkaline earth metal contents $\left[\mathrm{mg} \mathrm{l}^{-1}\right]$ in peat-moss-perlite (0), nonsaline (1) and saline (2) soils before planting and after harvesting the plants. Values are means $\pm \mathrm{SD}, n=3$; different letters indicate significant differences assessed by Fisher LSD test $(p \leq 0.05)$ after performing one-way ANOVA analysis.

\begin{tabular}{|c|c|c|c|c|c|c|}
\hline Treatment & $\mathrm{Mg}^{2+}$ & $\mathrm{Ca}^{2+}$ & $\mathrm{Na}^{+}$ & $\mathrm{K}^{+}$ & $\mathrm{K}^{+} / \mathrm{Na}^{+}$ & $\mathrm{pH}$ \\
\hline \multicolumn{7}{|c|}{ Before plant cultivation } \\
\hline Type (0) & $627 \pm 54^{\mathrm{a}}$ & $5,687 \pm 325^{a}$ & $1,072 \pm 106^{\mathrm{a}}$ & $4,636 \pm 376^{a}$ & 4.32 & 5.10 \\
\hline Type (1) & $29 \pm 3^{\mathrm{b}}$ & $10 \pm 1^{\mathrm{b}}$ & $26 \pm 3^{b}$ & $34 \pm 3^{b}$ & 1.28 & 8.00 \\
\hline Type (2) & $40 \pm 4^{c}$ & $187 \pm 12^{\mathrm{c}}$ & $382 \pm 25^{c}$ & $50 \pm 5^{\mathrm{c}}$ & 0.13 & 8.92 \\
\hline \multicolumn{7}{|c|}{ After harvesting of L. barbarum } \\
\hline Type (0) & $87 \pm 8^{\mathrm{a}}$ & $587 \pm 50^{\mathrm{a}}$ & $584 \pm 46^{\mathrm{a}}$ & $361 \pm 35^{\mathrm{a}}$ & 0.62 & 6.10 \\
\hline Type (1) & $52 \pm 4^{\mathrm{b}}$ & $201 \pm 19^{b}$ & $238 \pm 27^{b}$ & $88 \pm 7^{\mathrm{b}}$ & 0.37 & 7.20 \\
\hline Type (2) & $46 \pm 4^{c}$ & $151 \pm 12^{\mathrm{c}}$ & $244 \pm 21^{c}$ & $159 \pm 14^{c}$ & 0.65 & 7.40 \\
\hline \multicolumn{7}{|c|}{ After harvesting of L.chinense } \\
\hline Type (0) & $78 \pm 6^{\mathrm{a}}$ & $259 \pm 21^{\mathrm{a}}$ & $487 \pm 46^{\mathrm{a}}$ & $279 \pm 26^{\mathrm{a}}$ & 0.57 & 6.02 \\
\hline Type (1) & $51 \pm 4^{\mathrm{b}}$ & $220 \pm 18^{b}$ & $127 \pm 11^{\mathrm{b}}$ & $77 \pm 6^{\mathrm{b}}$ & 0.61 & 7.56 \\
\hline Type (2) & $84 \pm 7^{c}$ & $109 \pm 18^{b}$ & $238 \pm 23^{c}$ & $86 \pm 8^{c}$ & 0.36 & 7.30 \\
\hline
\end{tabular}


Table 3. Accumulation of alkaline and alkaline earth metal contents $\left[\mathrm{mg} \mathrm{g}^{-1}(\mathrm{DM})\right]$ in the roots of Lycium barbarum and Lycium chinense, grown on peat-moss-perlite (0), nonsaline soil (1), and saline soil (2). Values are means $\pm \mathrm{SD}, n=3$; different letters indicate significant differences assessed by Fisher LSD test $(p \leq 0.05)$ after performing one-way ANOVA analysis.

\begin{tabular}{lcllll}
\hline Treatment & $\mathrm{Mg}^{2+}$ & $\mathrm{Ca}^{2+}$ & $\mathrm{Na}^{+}$ & $\mathrm{K}^{+}$ & $\mathrm{K}^{+} / \mathrm{Na}^{+}$ \\
\hline After harvesting of $L$. barbarum & & & & \\
Type (0) & $0.88 \pm 0.09^{\mathrm{a}}$ & $7.48 \pm 0.67^{\mathrm{a}}$ & $1.84 \pm 0.06^{\mathrm{a}}$ & $18.78 \pm 1.75^{\mathrm{a}}$ & 10.21 \\
Type (1) & $2.00 \pm 0.20^{\mathrm{b}}$ & $5.40 \pm 0.46^{\mathrm{b}}$ & $1.84 \pm 0.11^{\mathrm{b}}$ & $6.96 \pm 0.59^{\mathrm{b}}$ & 4.67 \\
Type (2) & $2.71 \pm 0.32^{\mathrm{c}}$ & $7.39 \pm 0.59^{\mathrm{a}}$ & $2.95 \pm 0.22^{\mathrm{c}}$ & $11.15 \pm 1.09^{\mathrm{c}}$ & 3.78 \\
After harvesting of $L$. chinense & & & & \\
Type (0) & $1.27 \pm 0.11^{\mathrm{a}}$ & $9.13 \pm 0.87^{\mathrm{a}}$ & $2.88 \pm 0.26^{\mathrm{a}}$ & $9.02 \pm 0.85^{\mathrm{a}}$ & 3.13 \\
Type (1) & $1.95 \pm 0.20^{\mathrm{b}}$ & $11.04 \pm 1.09^{\mathrm{b}}$ & $1.51 \pm 0.13^{\mathrm{b}}$ & $13.42 \pm 1.11^{\mathrm{b}}$ & 8.89 \\
Type (2) & $2.06 \pm 0.22^{\mathrm{b}}$ & $8.58 \pm 0.79^{\mathrm{a}}$ & $1.77 \pm 0.14^{\mathrm{c}}$ & $11.50 \pm 1.12^{\mathrm{c}}$ & 6.50 \\
\hline
\end{tabular}

Table 4. Accumulation of alkaline and alkaline earth metal contents $\left[\mathrm{mg} \mathrm{g}^{-1}(\mathrm{DM})\right]$ in the shoots of Lycium barbarum and Lycium chinense, grown on peat-moss-perlite (0), nonsaline soil (1), and saline soil (2). Values are means $\pm \mathrm{SD}, n=3$; different letters indicate significant differences assessed by Fisher LSD test $(p \leq 0.05)$ after performing one-way ANOVA analysis.

\begin{tabular}{llllll}
\hline Treatment & $\mathrm{Mg}^{2+}$ & $\mathrm{Ca}^{2+}$ & $\mathrm{Na}^{+}$ & $\mathrm{K}^{+}$ & $\mathrm{K}^{+} / \mathrm{Na}^{+}$ \\
\hline \multicolumn{2}{l}{ After harvesting of $L$. barbarum } \\
Type (0) & $5.50 \pm 0.49^{\mathrm{a}}$ & $9.57 \pm 0.86^{\mathrm{a}}$ & $1.69 \pm 0.16^{\mathrm{a}}$ & $43.95 \pm 3.45^{\mathrm{a}}$ & 26.01 \\
Type (1) & $5.72 \pm 0.43^{\mathrm{b}}$ & $11.95 \pm 1.16^{\mathrm{b}}$ & $1.49 \pm 0.17^{\mathrm{a}}$ & $52.04 \pm 4.52^{\mathrm{b}}$ & 28.28 \\
Type (2) & $5.17 \pm 0.39 \mathrm{c}$ & $7.76 \pm 0.68^{\mathrm{c}}$ & $2.39 \pm 0.21^{\mathrm{b}}$ & $57.51 \pm 5.09^{\mathrm{c}}$ & 24.06 \\
After harvesting of L.chinense & & & & \\
Type (0) & $5.83 \pm 0.51^{\mathrm{a}}$ & $17.01 \pm 1.15^{\mathrm{a}}$ & $31.45 \pm 2.96^{\mathrm{a}}$ & $14.41 \pm 1.35^{\mathrm{a}}$ & 0.46 \\
Type (1) & $5.83 \pm 0.43^{\mathrm{a}}$ & $23.98 \pm 2.06^{\mathrm{b}}$ & $20.95 \pm 2.01^{\mathrm{b}}$ & $32.45 \pm 2.99^{\mathrm{b}}$ & 1.55 \\
Type (2) & $6.05 \pm 0.62^{\mathrm{a}}$ & $18.37 \pm 0.79^{\mathrm{c}}$ & $22.29 \pm 2.16^{\mathrm{b}}$ & $36.35 \pm 3.24^{\mathrm{c}}$ & 1.63 \\
\hline
\end{tabular}

Effect of soil salinity on Chl fluorescence parameters:

Fast Chl fluorescence (PF) is based on the emission from reaction centers of PSII after illumination with actinic red light (about $625 \mathrm{~nm}$ ). The "JIP" transient curves for plants grown on control soil are typical for non-stressed plants and all JIP characteristic points are clearly visible (Fig. 2). In $L$. barbarum and $L$. chinense, salinity stress resulted in the earlier appearance of $\mathrm{O}-\mathrm{J}$ phase, accompanied by a slight increase in $\mathrm{F}_{0}$ and the $\mathrm{J}$ peak (Fig. 2). The $\mathrm{O}-\mathrm{J}$ phase was further characterised by an early rise in the transient fluorescence curve, which was detected as K-band at about $300 \mu \mathrm{s}$. After salinity stress, a significant increase in $F_{p}$ ( $\mathrm{F}_{\mathrm{m}}$ - maximal fluorescence) and in the I-P phase was observed for L. chinense. In L. barbarum, $\mathrm{F}_{\mathrm{m}}$ decreased and a shift in the point $P$ from $300 \mathrm{~ms}$ towards later stages of the transient curve was observed.

Fig. 3 represents different parameters of PF, including $\Phi_{\mathrm{Po}}, \Phi_{\mathrm{Eo}}, \Phi_{\mathrm{Ro}}, \mathrm{DI}_{\mathrm{o}} / \mathrm{RC}, \mathrm{PI}_{\mathrm{ABS}}$, and $\mathrm{PI}_{\text {total }}$. Our results showed that salt stress lowered the parameters of $\Phi_{\mathrm{Po}}, \Phi_{\mathrm{Eo}}$, and $\Phi_{\text {Ro }}$ (Fig. 3A-C) in both plant species in a different way. Compared to $\Phi_{\mathrm{Po}}$ (where inhibition values reached $3.73 \%$ for $L$. barbarum and $0.54 \%$ for $L$. chinense of the control, respectively), the effect of salt stress on $\Phi_{\mathrm{E}}$ was much stronger $(23.6 \%$ and $5.4 \%$, respectively), whereas that on $\Phi_{\mathrm{Ro}}$ was smaller $(14.5 \%$ and $2.9 \%$, respectively). The $\mathrm{DI}_{\mathrm{o}} / \mathrm{RC}$ was stimulated during the salt stress $-37.6 \%$ and $13.0 \%$, respectively (Fig. $3 D$ ). The parameters $\mathrm{PI}_{\mathrm{ABS}}$ and $\mathrm{PI}_{\text {total }}$ are considered as the most sensitive among all parameters concerning the photosynthetic activity of
PSII and the efficiency of the electron transport reactions between PSII and PSI. In L. barbarum leaves, the values for these parameters decreased by about 57.0 and $48.9 \%$, while for $L$. chinense the reduction is 22.6 and $19.3 \%$, respectively (Fig. 3E,F).

\section{Discussion}

Seedling growth is normally limited by increasing concentration of $\mathrm{NaCl}$ (Sreenivasulu et al. 2000). Our results showed that with increasing salinity root and shoot DM of $L$. chinense increased, while root and shoot DM of L. barbarum decreased (Table 1). Time-dependent changes of growth and development of plants exposed to salt stress have been reviewed (Munns 2002). In the first few minutes, cells lose water and shrink, whereas over hours they regain their volume, but the expansion rates are limited. Over days and weeks, reduced cell elongation and cell division result in slower leaf appearance and inhibition of shoot growth. The shoot and root DM increased in L. chinense grown on saline soil in comparison to nonsaline soil. The shoot and root DM of $L$. barbarum grown on nonsaline soil were higher in comparison with control, but the results obtained for L. chinense were opposite (Table 1).

In the present study, we found that the accumulation of $\mathrm{Na}^{+}$in the leaves of $L$. chinense was higher than that of $L$. barbarum grown on control, nonsaline, and saline soils (Table 4). Besides salt exclusion in the roots, namely occurred at nonsaline soil (Table 2), low $\mathrm{Na}^{+}$contents in 


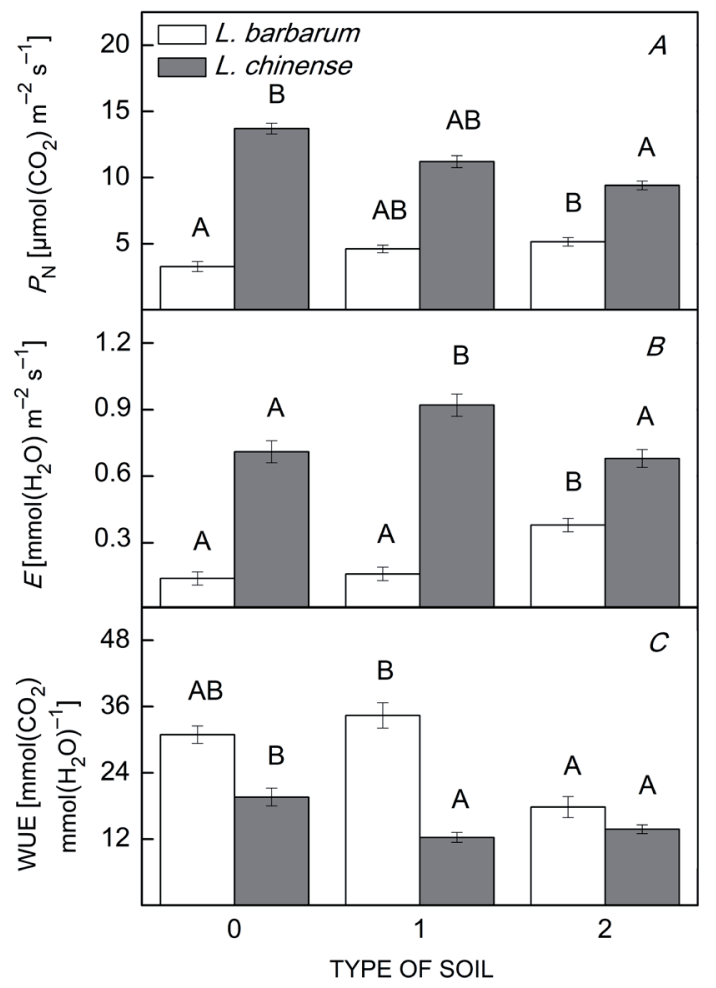

Fig. 1. Changes in: rate of net photosynthesis $\left(P_{\mathrm{N}}\right)-A$, transpiration rate $(E)-B$, and water-use efficiency (WUE) $-C$, measured in intact leaves from Lycium barbarum and Lycium chinense, cultivated for two vegetation seasons on peat-mossperlite (type 0), nonsaline (type 1), and saline (type 2) soils in a glasshouse. Mean values $\pm \mathrm{SD}(n=25)$. Values with the same letter are not significantly different when means are separated by Fisher`s LSD test $(p<0.05)$.

leaves can also be achieved by salt retention in the lower plant parts and also through abscission of old leaves once they accumulate large quantities of salts. Salt excretion is a very efficient avoidance mechanism, which occurs at the cell level, but also at whole organism level, and can be connected with the regulation of $\mathrm{K}^{+} / \mathrm{Na}^{+}$selectivity (Jeschke and Hartung 2000). Another mechanism, which prevents ion accumulation in the photosynthetic tissues, is an intraplant allocation that can keep an excess of salts within their roots and lower parts of the shoots (Dajič 2006). We observed yellowing and later abscission of older leaves in both plant species during the vegetation period. The leaf abscission was observed mainly in L. barbarum grown on the saline soil as compared to nonsaline soil; it can be considered as the avoidance mechanism by which younger leaves are preserved from the action of high salt concentrations.

The accumulation of $\mathrm{K}^{+}$and the ratio $\mathrm{K}^{+} / \mathrm{Na}^{+}$is higher in the leaves of $L$. barbarum grown on three types of substrates than that of L. chinense (Table 3). This ratio is an important selection criterion for salt tolerance (Ashraf and Orooj 2006). The $\mathrm{K}^{+} / \mathrm{Na}^{+}$ratio decreased by increasing salt concentration in safflower cultivars grown in perlite medium moistened by Hoagland's solution, but the highest values determined plant species more tolerant to salt stress (Erdal and Çakirlar 2014). The obtained ratio of $\mathrm{K}^{+} / \mathrm{Na}^{+}$

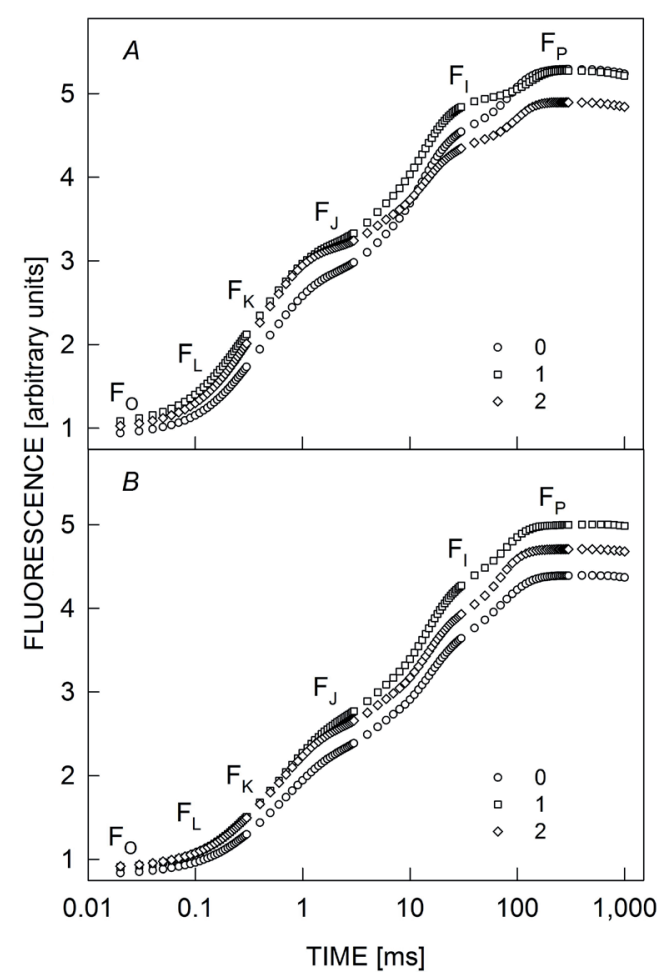

Fig. 2. Induction JIP curves of the fast chlorophyll fluorescence in intact leaves from Lycium barbarum $(A)$ and Lycium chinense $(B)$, cultivated for two vegetation seasons on peat-moss-perlite (type 0 ), nonsaline (type 1), and saline (type 2) soils in a glasshouse. Mean values $\pm \mathrm{SD}(n=5-7)$. Standard deviations are not shown for clearer view.

in L. barbarum was higher in comparison to L. chinense grown on control, nonsaline, and saline soils. Nevertheless, we found the enhanced root and shoot DM accumulation in L. chinense with increasing salinity (Table 1).

Salinity reduces $P_{\mathrm{N}}$ and $g_{\mathrm{s}}$ in most plant species (Ashraf and Shahbaz 2003, Koyro 2006). The $P_{\mathrm{N}}$ and $E$ were reduced under high salinity in the leaves of $L$. chinense, but in the leaves of $L$. barbarum, these parameters were enhanced slightly (Fig. 1A,B). The WUE changed negligibly in the leaves of $L$. chinense grown on nonsaline and saline soil, while in the leaves of $L$. barbarum it was reduced approximately twice under the same conditions (Fig. 1C). The investigations showed a strict correlation between plant growth and photosynthetic activity under saline conditions (Ashraf and O'Leary 1996, Koyro and Huchzermeyer 2004, Geissler et al. 2009). Biomass production depended mainly on the ability to keep a high net photosynthesis by low water loss rates; several plants revealed a combination of low $P_{\mathrm{N}}$, minimum $E$, high stomatal resistance, and minimum internal $\mathrm{CO}_{2}$ concentration at their threshold salinity tolerance. The results showed that balance between water loss and $\mathrm{CO}_{2}$ uptake helps to find a weak spot in the mechanism of adjustment of photosynthesis to high salinity (Badawi et al. 2004). Our results showed that in spite of lower $P_{\mathrm{N}}$ and $E$, measured in the leaves of $L$. chinense at the high saline level, these plants showed better water regime than that of $L$. barbarum under the same conditions (Fig. 1C). 


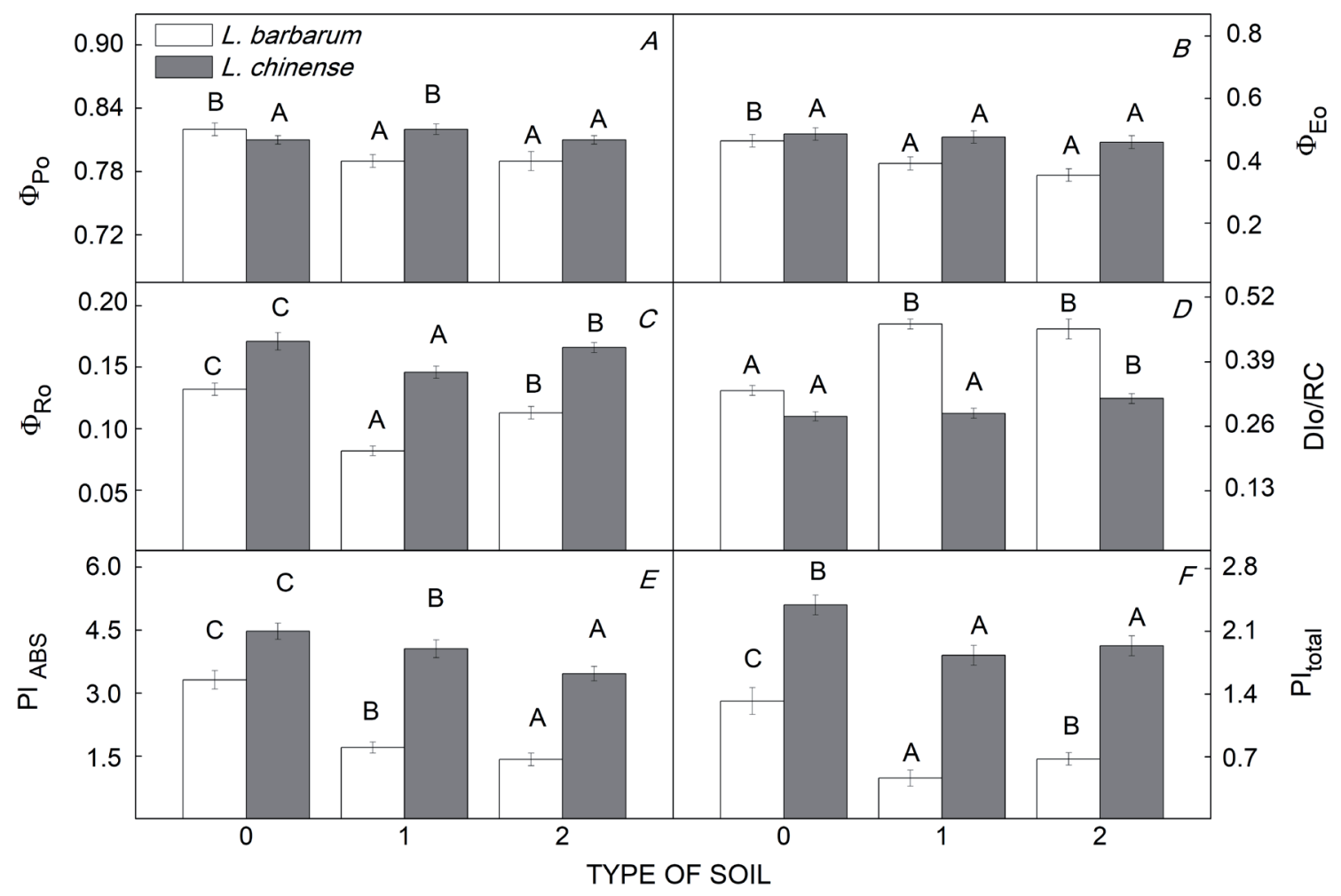

Fig. 3. Parameters of the fast chlorophyll fluorescence (quantum yield, energy dissipation, and performance index), measured in intact leaves of Lycium barbarum and Lycium chinense, cultivated for two vegetation seasons on peat-moss-perlite (type 0), nonsaline (type 1), and saline (type 2) soils in a glasshouse. Mean values $\pm \operatorname{SD}(n=5-7)$. Values with the same letter are not significantly different when means are separated by Fisher`s LSD test $(p<0.05)$.

We established a significant increase in $\mathrm{F}_{\mathrm{m}}\left(\mathrm{F}_{\mathrm{p}}\right)$ for L. chinense, but the decline in this parameter for L. barbarum after salinity stress (Fig. 2). It is well known that $\mathrm{F}_{\mathrm{m}}$ decreases in response to different stress conditions (Strauss et al. 2007, Strasser et al. 2010, Venkatesh et al. 2012) and this decrease is mainly due to denaturation of Chl-associated proteins including proteins of LHCII as well as D1 core protein of PSII (Yamane et al. 1997). In L. barbarum and L. chinense, salt stress resulted in the earlier appearance in $\mathrm{O}-\mathrm{J}$ phase, accompanied by a slight increase in $\mathrm{F}_{0}$ and $\mathrm{J}$ peak (Fig. 2). Such an initial increase of $\mathrm{F}_{0}$ is reported after drought stress in Haberlea rhodopensis (Strasser et al. 2010), cold stress in Arabidopsis thaliana (Mishra et al. 2011, Nellaepalli et al. 2012), and chilling stress in Arabis alpina (Kolaksazov et al. 2014). It is mostly due to the accumulation of reduced plastoquinone $\left(\mathrm{PQH}_{2}\right)$ (Tóth et al. 2005). Furthermore, the large amount of reduced $\mathrm{PQH}_{2}$ after chilling stress in A. thaliana is accompanied by partial blocking of the electron flow from PSII to PSI, thus leading to phosphorylation of LHCII (Nellaepalli et al. 2012). Phosphorylation of LHCII causes dissociation of this complex from PSII and presumably protects plants from excessive light, through a migration of LHCII to PSI (Nellaepalli et al. 2012). Reduced $\mathrm{PQH}_{2}$ was accumulated too after moderate heat stress in A. thaliana and facilitated LHCII phosphorylation (Nellaepalli et al. 2011).

The $\mathrm{O}-\mathrm{J}$ phase can be further characterised by an early rise in the transient fluorescence curve, which is detected at about $300 \mu \mathrm{s}$ (Strasser et al. 2004). This rise is called
$\mathrm{K}$-band and is widely accepted as a sign of dissociation of the oxygen-evolving complex (OEC) (Guissé et al. 1995). Our results showed that after salt stress, a slight decrease in $\mathrm{F}_{\mathrm{m}}$ and in the I-P phase occurred in L. barbarum (Fig. 2). Normally, the last part of the JIP curve represents a reduction of the end electron acceptors from the PSI side (Schreiber et al. 1989, Schansker et al. 2003). The decrease of I-P phase, which is accompanied with a decrease of $F_{p}$, could be due to a strong inhibition of the PSI acceptor side and was observed in pea (Schansker et al. 2005). In our experiments, the decline was observed with increasing salinity level only in L. barbarum. During salt stress, the JIP-curves for L. chinense did not change as compared with control. Additionally, the I-P phase and the P peak increased more for the nonsaline soil than that for saline soil in L. chinense (Fig. 2).

PSII activity can be further investigated by calculating other parameters of PF (Fig. 3). Briefly, $\Phi_{\mathrm{Po}_{0}}$ can be considered as one of the most stable photosynthetic parameters and it is widely used in monitoring the effect of different environmental stresses on photosynthetic behaviour in plants (Strasser et al. 2004). $\Phi_{\mathrm{P}_{\mathrm{o}}}$ is related to the deactivation or full degradation of PSII reaction centers and for that reason. Consequently, the insignificantly changing of this parameter (between nonsaline and saline soil) indicated that PSII was not affected by the salt (Fig. $3 B, C$ ). Thus, our results confirmed the accumulated body of evidence that parameters of $\Phi_{\mathrm{Eo}}$ and $\Phi_{\mathrm{Ro}}$, which reflect process in the photosynthetic electron chain closer to PSI, were more 
sensitive to salt compared to $\Phi_{\mathrm{Po}}$ (Venkatesh et al. 2012). Concerning the energy dissipation flux per reaction center of PSII $\left(\mathrm{DI}_{\mathrm{o}} / \mathrm{RC}\right)$, representing the amount of energy, which the plant is not able to utilize in photochemical reactions, our results showed that this parameter was mostly stimulated in L. barbarum compared to L. chinense (Fig. 3D). In L. barbarum samples, both parameters $-\mathrm{PI}_{\mathrm{ABS}}$ and $\mathrm{PI}_{\text {total }}$ decreased strongly, while in L. chinense, the reduction was 2.5 times lower (Fig. $3 E, F$ ).

Several conclusions could be drawn from these results. (1) The performance index $\left(\mathrm{PI}_{\mathrm{ABS}}\right)$, which represents the overall activity of PSII and the intersystem electron flow, was strongly inhibited in L. barbarum during salt stress, but it was not correlated with its effect on $\mathrm{CO}_{2}$ net photosynthesis. (2) The quantum yield of the primary photochemical reaction $\left(\Phi_{\mathrm{P}_{\mathrm{o}}}\right)$ of PSII displayed the lowest decline among all PF parameters, thus indicating higher tolerance of PSII to salt stress in both Lycium species. (3) The electron transport between PSII and PSI as revealed by the quantum yield $\Phi_{\mathrm{Eo}}$ was more inhibited in L. barbarum than that in L. chinense. (4) The electron transport to the end electron acceptors of PSI as revealed by the quantum yield $\Phi_{\text {Ro }}$ was inhibited to a great extent in L. barbarum than that in L. chinense. (5) We can assume that during salt stress in L. barbarum, enhanced amount of reduced $\mathrm{PQH}_{2}$ is accumulated, which leads to lower rate of the electron transport to PSI. All these changes in the intermediate electron transport and especially in the function of PSI can be considered as a protection mechanism against accumulation of ROS in the photosynthetic apparatus during salt stress. L. chinense is more tolerant than L. barbarum in spite of higher accumulation of $\mathrm{Na}^{+}$in the leaves of $L$. chinense compared to L. barbarum grown on control, nonsaline, and saline soils. With increasing salinity level, root and shoot dry mass of $L$. chinense increased, while root and shoot dry mass of $L$. barbarum decreased.

\section{References}

Ashraf M., O'Leary J.W.: Responses of some newly developed salt-tolerant genotypes of spring wheat to salt stress. 1. Yield components and ion distribution. - J. Agron. Crop Sci. 176: 91-101, 1996.

Ashraf M, Orooj A.: Salt stress effects on growth, ion accumulation and seed oil concentration in an arid zone traditional medicinal plant ajwain (Truchys permumammi [L.] Spraque). - J. Arid Environ. 64: 209-220, 2006.

Ashraf M., Shahbaz M.: Assessment of genotypic variation in salt tolerance of early CIMMYT hexaploid wheat germplasm using photosynthetic capacity and water relations as selection criteria. - Photosynthetica 41: 273-280, 2003.

Badawi G.H., Kawano N., Yamauchi Y. et al.: Overexpression of ascorbate peroxidase in tobacco chloroplasts enhances the tolerance to salt stress and water deficit. - Physiol. Plantarum 121: 231-238, 2004.

Bernardello L.M.: [Taxonomic revision of the South American species of Lycium (Solanaceae)] - Bol. Acad. Nac. Cienc Córdoba 57: 173-356, 1986. [In Spanish]

Dajič Z.: Salt stress. - In: Rao K.V.M., Raghavendra A.S., Reddy K.J. (ed.): Physiology and Molecular Biology of Stress Tolerance in Plants. Pp. 41-99. Springer, Dordrecht 2006.

Dimitrova V., Georgieva T., Markovska Y.: Influence of salt stress on some physiological characteristics of two Lycium varieties grown ex vitro in hydroponic. - Annu. Univ. Sofia Fac. Biol. 101: 141-148, 2016.

Doumett S., Lamperi L., Checchini L.et al.: Heavy metal distribution between contaminated soil and Paulownia tomentosa in a pilot-scale assisted phytoremediation study: influence of different complexing agents. - Chemosphere 72: 1481-1490, 2008.

Erdal S.Ç., Çakirlar H.: Impact of salt stress on photosystem II efficiency and antioxidant enzyme activities of safflower (Carthamus tinctorius L.) cultivars. - Turk. J. Biol. 38: 549$560,2014$.

Geissler N., Hussin S., Koyro H.-W.: Elevated atmospheric $\mathrm{CO}_{2}$ concentration ameliorates effects of $\mathrm{NaCl}$ salinity on photosynthesis and leaf structure of Aster tripolium L. - J. Exp. Bot. 60: 137-151, 2009.

Goltsev V., Kalaji H., Kouzmanova M. et al.: Variable and Delayed Chlorophyll $a$ Fluorescence. Basics and Application in Plant Sciences. Pp. 220. Inst. Comp. Sci., MoscowIzshevsk 2014.

Guissé B., Srivastava A., Strasser R.J.: The polyphasic rise of the chlorophyll $a$ fluorescence (O-K-J-I-P) in heat stressed leaves. - Arch. Sci. 48: 147-160, 1995.

Ivanova K., Dimitrova V., Georgieva T.et al.: Effect of soil salinity on growth, gas exchange and antioxidant defence of two Paulownia lines. - Genet. Plant Physiol. 4: 163-173, 2014.

Jeschke W.D., Hartung W.: Root-shoot interactions in mineral nutrition. - Plant Soil 226: 57-69, 2000.

Kolaksazov M., Laporte F., Goltsev V. et al.: Effect of frost stress on chlorophyll a fluorescence and modulated $820 \mathrm{~nm}$ reflection in Arabis alpina population from Ril amountain. Genet. Plant Physiol. 4: 44-56, 2014.

Kosová K., Vítámvás P., Prášil I.T. et al.: Plant proteome changes under abiotic stress - contribution of proteomics studies to understanding plant stress response. - J. Proteom. 74: 13011322, 2011.

Koyro H.W.: Effect of salinity on growth, photosynthesis, water relations and solute composition of the potential cash crop halophyte Plantago coronopus (L.). - Environ. Exp. Bot. 56: 136-146, 2006.

Koyro H.-W., Huchzermeyer B.: Ecophysiological needs of the potential biomass crop Spartina townsendii Grov. - Trop. Ecol. 45: 123-139, 2004.

Koyro H.-W., Huchzermeyer B., Zörb Ch.: Effects of hyperosmotic salinity on protein patterns and enzyme activities. - In: Pessarakli M. (ed.): Handbook of Plant and Crop Physiology. Pp. 487-507, Taylor \& Francis Group LLC, CRC Press, Boca Raton 2014.

Levin R.A., Miller J.S.: Relationships within tribe Lycieae (Solanaceae): paraphyly of Lycium and multiple origins of gender dimorphism. - Am. J. Bot. 92: 2044-2053, 2005.

Liu N., Guan L.: Linkages between woody plant proliferation dynamics and plant physiological traits in southwestern North America. - J. Plant Ecol. 5: 407-416, 2012.

Miller J.S.: Phylogenetic relationships and the evolution of gender dimorphism in Lycium (Solanaceae). - Syst. Bot. 27: 416-428, 2002.

Mishra A., Mishra K.B., Höermiller I.I. et al.: Chlorophyll fluorescence emission as a reporter on cold tolerance in Arabidopsis thaliana accessions. - Plant Signal. Behav. 62: 301-310, 2011.

Munns R.: Comparative physiology of salt and water stress. Plant Cell Environ. 25: 239-250, 2002.

Munns R.: Plant adaptations to salt and water stress: differences and commonalities. - Adv. Bot. Res. 57: 1-32, 2011. 
Munns R., Richards R.A.: Recent advances in breeding wheat for drought and salt stresses. - In: Jenks M.A., Hasegawa P.M., Jain S.M. (ed.): Advances in Molecular Breeding towards Salinity and Drought Tolerance. Pp. 565-585. Springer, New York 2007.

Nellaepalli S., Kodru S., Subramanyam R.: Effect of cold temperature on regulation of state transitions in Arabidopsis thaliana. - J. Photoch. Photobio. B 112: 23-30, 2012.

Nellaepalli S., Mekala N.R., Zsiros O. et al.: Moderate heat stress induces state transitions in Arabidopsis thaliana. - BBABioenergetics 1807: 1177-1184, 2011.

Petrova A., Vladimirov V., Georgiev V.: [Invasive Alien Species of Vascular Plants in Bulgaria.] Pp. 320. IBER - BAS, Sofia 2013. [In Bulgarian]

[Referative basic data for the soils in Bulgaria.] Pp. 280. Agricultural Academy, Sofia 2009. [In Bulgarian]

Schansker G., Srivastava A., Govindjee G. et al.: Characterization of the $820-\mathrm{nm}$ transmission signal paralleling the chlorophyll $a$ fluorescence rise (OJIP) in pea leaves. - Funct. Plant Biol. 30: 785-796, 2003.

Schansker G., Tóth S.Z., Strasser R.J.: Methylviologen and dibromothymoquinone treatments of pea leaves reveal the role of photosystem I in the in the chl $a$ fluorescence rise OJIP. - Biochim. Biophys. Acta 1706: 250-261, 2005.

Schreiber U., Neubauer C., Klughammer C.: Devices and methods for room-temperature fluorescence analysis. Philos. T. Roy. Soc. B 323: 241-251, 1989.

Sreenivasulu N., Grimm B., Wobus U., Weschke W.: Differential response of antioxidant compounds to salinity stress in salttolerant and salt-sensitive seedlings of foxtail millet (Setaria italic). - Physiol. Plantarum 109: 435-443, 2000.

Stirbet A., Riznichenko G.Yu., Rubin A.B. et al.: Modelling chlorophyll $a$ fluorescence transient: relation to photosynthesis. - Biochemistry-Moscow+ 79: 291-323, 2014.
Strasser R.J., Srivastava A., Govindjee G.: Polyphasic chlorophyll a fluorescent transient in plants and cyanobacteria. Phytochem. Photobiol. 61: 32-42, 1995.

Strasser, R.J. Tsimilli-Michael M., Qiang S. et al.: Simultaneous in vivo recording of prompt and delayed fluorescence and 820$\mathrm{nm}$ reflection changes during drying and after rehydration of the resurrection plant Haberlea rhodopensis. - Biochim. Biophys. Acta 1797: 1313-1326, 2010.

Strasser R.J., Tsimilli-Michael M., Srivastava A.: Analysis of the chlorophyll $a$ fluorescence transient. - In: Papageorgiou G.C., Govindjee R. (ed.): Chlorophyll a Fluorescence: A Signature of Photosynthesis. Advances in Photosynthesis and Respiration. Pp. 321-362. Kluwer Academic Publishers, Dordrecht 2004.

Strauss J.A., Krüger G.H.J., Strasser R.J. et al.: The role of low soil temperature in the inhibition of growth and PSII function during dark chilling in soybean genotypes of contrasting tolerance. - Physiol. Plantarum 131: 89-105, 2007.

Tóth S. Z., Schansker G., Strasser R. J.: In intact leaves, the maximum fluorescence level $F_{M}$ is independent of the redox state of the plastoquinone pool: A DCMU-inhibition study. BBA-Bioenergetics 1708: 275-282, 2005.

Venkatesh J., Upadhyaya C.P., Yu J.W. et al.: Chlorophyll $a$ fluorescence transient analysis of transgenic potato overexpressing D-galacturonic acid reductase gene for salinity stress tolerance. - Hortic. Environ. Biote. 534: 320-328, 2012.

Yamane Y., Kashino Y., Koike H. et al.: Increases in the fluorescence $\mathrm{F}_{0}$ level and reversible inhibition of photosystem II reaction center by high-temperature treatments in higher plants. - Photosynth. Res. 52: 57-64, 1997.

Zheng G.-Q., Zheng Z.-Y., Xu X. et al.: Variation in fruit sugar composition of Lycium barbarum L. and Lycium chinense Mill. of different regions and varieties. - Biochem. Syst. Ecol. 38: $275-284,2010$.

(C) The authors. This is an open access article distributed under the terms of the Creative Commons BY-NC-ND Licence. 